\title{
JULIA KRISTEVA: TEORÍA, PROCESO E INTERPRETACIÓN DEL SENTIDO
}

\section{Douglas Bohórquez}

\author{
Universidad de los Andes. Núcleo \\ Universitario «Rafael Rangel». Trujillo
}

Originaria de Bulgaria donde nació en 1941, Julia Kristeva se instala en el horizonte intelectual francés a partir de la publicación de un libro profundamente audaz y renovador que despertará la atención y la polémica en Francia pero también en otras partes del mundo donde se discuta sobre las últimas tendencias de la crítica literaria y semiótica. Nos referimos a Semiótica. Investigaciones en torno al semanálisis (Kristeva, 1969b). Kristeva había llegado a París en 1965 con una beca de estudios, en el marco de acuerdos franco-búlgaros con la intención de obtener su doctorado de tercer ciclo en literatura francesa y comparada. Ingresa a la Escuela Práctica de Altos Estudios y sigue cursos con Lucien Goldman quien dirige su doctorado de tercer ciclo sobre los orígenes del discurso novelesco en Francia.

Seducida por el universo estructuralista de Roland Barthes sigue también sus cursos. Son los años 66-67, vísperas del famoso mayo de 
1968. En la atmósfera de las incitantes discusiones en torno al estructuralismo y la crítica universitaria erudita Kristeva se acerca a la obra de Jakobson, Levi-Strauss, Benveniste y Greimas, cuyos trabajos cobran cada vez más incidencia y relevancia.

En 1966, por intermedio de Gerard Genette, compañero de seminario, conoce a Philippe Sollers, novelista y teórico también de vanguardia y a través de él se afilia al grupo Tel Quel. Se vincula estrechamente al ámbito de sus discusiones y forma parte, al lado de Barthes y del propio Sollers del comité de redacción de Tel Quel, revista que ocupará un espacio significativo en el debate crítico de la década del 70.

Para Kristeva el estructuralismo se convirtió pronto en una adquisición más o menos institucional. Después del entusiasmo de sus novedosos planteamientos, se va generando todo un cúmulo de interrogaciones y observaciones que le conducen a la crítica de sus conceptos y hallazgos fundamentales y en particular a la idea de «dinamizar la estructura tomando en consideración el sujeto hablante y su experiencia inconsciente por una parte y las presiones de las otras estructuras por otra parte» (Kristeva, 1983: 44).

Es este precisamente un planteamiento central que encontramos desde su Semiótica. Investigaciones en torno a un semanálisis (Kristeva, 1969) hasta su Polylogue (Kristeva, 1977) pasando por La Revolution du langage poétique (Kristeva, 1974a), monumental análisis de la vanguardia de fines del siglo XIX. Nos referimos a su idea del sujeto escritor (autor) como sujeto hablante que cuestiona o pone en proceso el lenguaje, generando una suerte de conmoción que puede afectar tanto niveles del habla cotidiana como la tradición literaria a la que su trabajo se adscribe.

Hay en este sentido, pues, por lo menos dos grandes líneas de trabajo en la producción teórico-crítica de Kristeva. Una primera vertiente que pudiéramos caracterizar como de orientación epistemológica, se preocupa por los problemas teóricos y metodológicos de la semiótica en tanto que ciencia crítica y/o crítica de la ciencia (Kristeva, 1969b: 47-42) y por elaborar una suerte de ciencia del texto o teoría semiológica de los textos. Es ésta una fase de indagación sobre el lenguaje y la linguiística y de búsqueda de una semiótica de los translenguajes o prácticas significantes complejas como la literatura. Algunas de las investigaciones relativas a esta vertiente de trabajo se apoyan y se generan en torno al análisis de autores y momentos fundamentales de la producción literaria francesa. 
La segunda línea de investigación de Kristeva indaga en los procesos de interpretación del sentido y de la cultura. A ella nos referiremos más adelante.

Se inicia la búsqueda de orientación epistemológica pero también de práctica analítica literaria con un primer libro publicado bajo seudónimo (Julia Joyaux): El lenguaje, este desconocido (Kristeva, 1969a), suerte de mirada histórica y conceptual al desarrollo de la linguística. Esta línea de investigación continúa con la publicación de Semiótica. En torno al semanálisis (Kristeva, 1969b), sigue con El texto de la novela (Kristeva, 1970), avanza con La revolution du langage poétique (Kristeva, 1974a), continúa con Polylogue (Kristeva, 1977) y se extiende hasta uno de sus más recientes libros: Les temps sensible (Proust et l'experience littéraire) (Kristeva, 1994).

Apoyándose en una revisión crítica de los postulados de los formalistas rusos y de las nociones de la linguística de Saussure (signo, arbitrariedad, lengua/habla, significación) así como en las ideas matrices de la obra de Bakthine (a quien traduce y da a conocer en Francia), Kristeva propone una concepción de la práctica literaria (moderna, fundamentalmente) como trabajo de la lengua. Nos encontramos de este modo con uno de los conceptos básicos de su teoría semiológica del texto literario. Para Kristeva el trabajo transgresivo del escritor sobre la lengua y sobre la tradición literaria convierte al lenguaje en sujeto en proceso, es decir, ocurre la distorsión de los signos y de sus estructuras y por lo tanto la multiplicación y proliferación del sentido.

Así concebido, el texto resulta por lo tanto de una búsqueda e interrogación del lenguaje y de la exploración de la tradición de la cual él deriva. El texto no puede entenderse fuera de la productividad abierta e infinitizada del sentido que el proceso deconstructor e intertextual implica.

De este modo la teoría semiológica de Kristeva insiste en el análisis de la materialidad significante del texto y de la producción del sentido que el trabajo en/sobre la lengua comporta. Visto en esta dimensión semiótica el texto es esta suerte de aparato translinguiístico que redistribuye el orden de la lengua «poniendo en relación la superficie de un habla comunicativa que apunta a la información directa con diferentes tipos de enunciados anteriores o sincrónicos» (Kristeva, 1969b: 76).

En su relación con la lengua el texto es este translenguaje que la cuestiona, que «la despega de su inconsciente y del automatismo de su desenvolvimiento habitual» (Kristeva, 1969b: 26). 
Travesía de la lengua y travesía del sentido el texto ya no es para Kristeva sólo un sistema o estructura de signos, sino también y fundamentalmente, un proceso de lenguaje. Un sujeto en proceso que permite mostrar lo que pudiéramos llamar el revés de la trama, esa otra escena de la lengua trabajada por el descentramiento y la ambivalencia del sentido.

Este descentramiento y travesía del sentido en el proceso textual será leído a través de algunas nociones que constituyen lo que pudiéramos llamar el núcleo conceptual de esta teoría semiológica kristeveana. Estas nociones o conceptos son:
a. Genotexto/fenotexto.
b. Significancia.
c. Semiótico/simbólico.
d. Chora (semiótica).
e. Heterogeneidad.
f. Negatividad.

La explicación teórica, profundización y aplicación de estos conceptos a la lectura de la vanguardia literaria francesa de fines del siglo XIX es el objeto precisamente de esa investigación extraordinaria que es La révolution du languaje poétique (Kristeva, 1974a). La teoría semiológica de la escritura es en este libro lectura de los fundamentos semanalíticos del texto, de la constitución en su interior del sentido, en lucha contra la heterogeneidad semiótica y pulsional y contra la negatividad y rechazo que imponen las estructuras lógicas del lenguaje. Lectura por lo tanto de ese proceso del sentido que configura al texto moderno como sujeto en crisis, en proceso.

Esta línea de reflexión teórico-crítica, epistemológica, de hecho corre paralela con una segunda línea que pudiéramos denominar de interpretación, la cual tiene antecedentes en seminarios dirigidos por Kristeva en la Universidad de París VII, abiertos a la participación de otros investigadores. El primero de estos seminarios se propuso realizar una apertura hacia la reflexión sobre el lenguaje y los modos de significación de otras culturas y otras civilizaciones: la China, la India, el Islam, el Judaismo. El segundo, realizado fuera del recinto universitario, en el hospital de la ciudad universitaria de París, tuvo como tema central el análisis de la verdad y de la verosimilitud del texto psicótico y marcó una pauta de trabajo en la que cada vez tendrá más incidencia el psicoanálisis. 
Esta línea de interpretación se abrirá también hacia los problemas relativos a la condición femenina, pero fundamentalmente se irá delimitando en torno a lo que pudiéramos llamar el análisis de las experiencias límites (la locura, el horror, la abyección, el amor, la melancolía, la depresión, el exilio o extranjería), privilegiando cada vez más, como hemos dicho, la reflexión y la orientación psicoanalítica.

La consideración de la situación de la mujer china en el contexto de la Revolución Socialista es abordado por Kristeva en un libro que denominará: Las Chinas (1974b). Suerte de análisis socio-cultural y antropológico de las condiciones de la mujer atrapada en una red de prescripciones, normas y tabúes, el libro se abre igualmente a una serie de interrogantes sobre el futuro de la mujer en el contexto de esa otra sociedad que emerge para ese momento de la Revolución en China.

Entrando ya de un modo sistemático en el análisis de las experiencias límites, Poderes del Horror (Kristeva, 1980), introduce en la crítica el concepto de abyección, examinándolo en sus significaciones bíblicas y antropológicas y refiriéndolo a autores fundamentales de la modernidad literaria (Proust, Joyce, Borges, Artaud) y en particular a Luis Ferdinand Celine, de cuyo universo literario el libro es un detenido análisis semiológico. En Pouvoirs de l'horreur, la mirada analítica recorre esas formas y espacios del sujeto en crisis que son el asco, el dolor, la impureza, el horror. La literatura moderna y particularmente la obra de Celine le permiten a Kristeva estudiar los mecanismos y formas discursivas a través de las cuales la abyección se enuncia y se enmascara.

El escritor -indica Kristeva - que llega a fascinarse por lo abyecto «se imagina su lógica, se proyecta en ella, la introyecta y por ende pervierte la lengua -el estilo y el contenido- (Kristeva, 1980: 23). Sugiriendo la idea de que la literatura es el significante privilegiado de la abyección, Kristeva intenta mostrar que lejos de ser un margen menor de nuestra cultura, la literatura de lo abyecto «es la codificación última de nuestras crisis, de nuestros apocalipsis más íntimos y más graves».

La práctica psicoanalítica le ha permitido a Kristeva proseguir su investigación de esta subjetividad en proceso que se puede captar siguiendo esa trama secreta de las dislocaciones, rupturas o re-composiciones figurativas del lenguaje. Se trata de la escucha de esa otra escena del discurso en la que el sueño y el deseo tejen sus alianzas. Es lo que podemos ver a través de su análisis del discurso amoroso. De las consideraciones en torno al discurso de lo abyecto al estudio del discurso amoroso Kristeva encuentra ese mismo sujeto polimórfico 
que se revela en las grietas del lenguaje, en esas fisuras que lo semiótico abre sobre lo simbólico.

Historias de Amor (Kristeva, 1983) en efecto, retoma el análisis del discurso amoroso en el camino abierto por Freud, a partir de la asociación que éste estableció con el narcisismo. Kristeva, desde la perspectiva del sujeto hablante, se abre hacia ese horizonte de interrogaciones que suscita el discurso amoroso y su profunda imbricación en el inconsciente y en lo imaginario.

Así, desde el análisis del amor bíblico y del eros griego y su transsformación en ágape, las observaciones en torno al amor natural y el amor a sí mismo en Santo Tomás, el amor cortés, el amor-odio en Romeo y Julieta, hasta el estudio de las formas discursivas modernas del amor en Stendhal, Baudelaire y Bataille, Historias de amor se configura como toda una travesía analítica por los diversos rostros y modalidades significantes del amor. Para Kristeva Narciso es hoy «un exiliado, privado de su espacio psíquico, un extraterrestre de aspecto prehistórico falto de amor». Es decir, la modernidad de nuevo transforma, hace de Narciso ese E.T. que somos todos: «... niño confuso, desollado, un tanto repugnante, sin cuerpo ni imagen precisos que, habiendo perdido un hábitat propio, extranjero en un universo de deseo y de poder, sólo aspira a reinventar el amor» '. Polivalente, indecidible, infinito, el discurso amoroso es para Kristeva también como la poesía, vértigo de palabras, sujeto en proceso.

En un libro posterior, Soleil Noir (Kristeva, 1987) continúa su investigación en la línea psicoanalítica interesándose en el análisis de la melancolía y de las figuras de la depresión femenina. El tema de la depresión le conduce de nuevo al mito de Narciso...: «la depresión es el rostro oculto de Narciso, el que tendrá en la muerte pero que ignora, mientras se admira en un espejo» (Kristeva, 1987: 15). Pero el objetivo hacia el que conduce la rigurosa delimitación psicoanalítica de estos conceptos es la escritura literaria: Nerval, Dostoievski, Duras.

Del amor a la melancolía, una misma obsesión por pensar el lenguaje, particularmente el de la literatura, su proceso del sentido, atraviesa la producción intelectual de Kristeva. Aún cuando hay un evidente privilegio del saber psicoanalítico en la exploración y conocimiento de estas experiencias límites del ser humano (la abyección, el amor, la depresión, la melancolía) Kristeva no ha abandonado sin embargo la perspectiva semiológica.

1 Historias de amor (Kristeva, 1988: 339), citado según la traducción al español. 
La línea de interpretación psicoanalítica delimita una trayectoria de búsqueda en la que la reflexión sobre el mismo psicoanálisis se alterna con el trabajo sobre pacientes y con la lectura de textos y autores de la literatura francesa fundamentalmente (Celine, Baudelaire, Stendhal, Bataille, Nerval, Duras). En este ámbito de interrogaciones y certezas en torno al psicoanálisis da a conocer su Au commencement etait l'amour. Psichanalyse et foi (Kristeva, 1985).

Histoires d'amour y Soleil Noir confirman el camino del psicoanár lisis, como la vía más adecuada para acercarse a ese discurso secreto, desviado, del sujeto, en el que en ocasiones se encuentra atrapado, a la vez que posibilitan, desde la perspectiva del amor y la melancolía, respectivamente, una nueva lectura de textos y autores claves de la literatura europea moderna. $Y$ hemos dicho que Kristeva no ha abandonado la perspectiva semiológica porque el lenguaje continúa siendo el tema en cuestión de sus investigaciones, interrogado desde sus más profundos, íntimos y a veces dolorosos abismos pero también desde sus más altas realizaciones estéticas y literarias (Celine, Baudelaire, Stendhal, Bataille, Nerval, Dostoievsky, Duras). Si el psicoanálisis le permite a Kristeva escuchar esto que ella ha denominado la salvajería del ser hablante, la mirada semiológica penetra los textos explorando el proceso del sentido, proceso heterogéneo, plural, que ninguna otra disciplina aislada, sometida a una única dirección de acceso, podría pensar.

En Extranjeros a nosotros mismos (Kristeva, 1988) interroga los supuestos que han fundado, a través de distintos tipos y formas de sociedades, nuestra relación con ese otro que es el extranjero. Analiza el tratamiento, las concepciones, las formas políticas que desde la Grecia antigua hasta la Francia de hoy se han utilizado para separar o trazar normas con respecto al extranjero, ese individuo que cuando no se le utiliza o se le integra en el trabajo productivo, se le tiene como una amenaza. Pero también el análisis de Kristeva discurre hacia ese otro extranjero que está en nosotros, hacia ese exilio interior, esa inquietante extrañeza como dijera Freud, que aún en nuestro propio país puede habitarnos y dolernos.

Desde el punto de vista del estilo Extranjeros a nosotros mismos insiste en esa tendencia cada vez más marcada en la producción de Kristeva hacia una escritura ensayística. Escritura crítica que configura, desde el psicoanálisis y la semiología, una rigurosa interpretación de la cultura, a partir de la decodificación de los signos de su extrañamiento y perversión. En esta búsqueda interpretativa se inscriben, 
como hemos señalado, sus investigaciones sobre la presencia y situación de la mujer en la revolución socialista china, sobre la locura, el horror, el amor, la depresión y la melancolía, la extranjería y lo que ha denominado en uno de sus últimos libros Las nuevas enfermedades del alma (Kristeva, 1993).

Estas dos vertientes de las que hemos hablado en la producción intelectual de Kristeva (la vertiente de búsqueda semiológica y de análisis del proceso textual y la vertiente ensayística, que privilegia la reflexión psicoanalítica) convergen y alcanzan unidad en lo que se puede considerar uno de los más relevantes proyectos actuales de interpretación y análisis de la cultura a partir de la exploración del entramado secreto de sus signos.

Vista en su conjunto la obra de Kristeva se nos presenta como el proyecto de una semiología que, partiendo de la discusión y cuestionamiento de sus propios métodos y objetos de trabajo, no ha cesado de interrogar el sentido en sus diversas modalidades de producción crítica. Desde la investigación textual, semiológica o psicoanalítica es ese proceso crítico del sentido y su sujeto - proceso de la heterogeneidad, de la significancia y de la negatividad- lo que los análisis de Kristeva revelan como una de sus más significativas constantes. La lectura de la cultura aparece entonces como lectura de la crisis del sentido y del sujeto que éste configura en los textos o a través de esas perversiones del lenguaje que teje el poder en la locura, el horror, el amor o el exilio:

la experiencia cotidiana parece demostrar una reducción espectacular de la vida interior. Quién sigue teniendo un alma en nuestros días?... presionados por el estrés, impacientes por graves gastos, por gozar y morir, los hombres y las mujeres de hoy prescinden de esta representación de su experiencia que llamamos una vida psíquica. El acto y su doble, el abandono, sustituyen a la interpretación del sentido (Kristeva, 1993: 14).

Toda la producción teórico-crítica de Kristeva se nos presenta como una búsqueda obsesiva del sentido, de su lógica oculta detrás de los textos o detrás del discurso de los sujetos hablantes. De la lectura de la Biblia a la lectura de las pasiones y terrores del hombre moderno toda su obra pregunta por el sujeto que habla, por su discurso tramado de imágenes y deseos, de fantasía y realidad, por ese proceso del sentido tramado también por la palabra del otro. 


\section{Referencias bibliográficas}

KRISTEVA, J. (1969a). Le langage, cet inconnu. S.G.P.P (Publicado bajo seudónimo. Reapareció firmado por Kristeva en 1981, París: Editions du Seuil, Col Points).

- (1969b). Semiotiké Recherches pour une semanalyse. París: Du Seuil, Col Tel Quel (Traducción al español: Semiótica I y II. (1981). Madrid: Fundamentos.

- (1970). Le texte du roman. Approche sémiologique d'une structure discursive transformationnelle. La Haya: Mouton (Traducción al español: El texto de la novela. Barcelona: Lumen. 1974).

- (1974a). La révolution du langage poétique. L'avant-garde à la fin du XIX siècle: Lautréamont et Mallarmé: París. Du Seuil, Col. Tel Quel.

- (1974b). Des Chinoises. París: Des Femmes.

- (1975). La traversée des signes (obra colectiva). París: Du Seuil, Col Tel Quel.

- (1977). Polylogue. París: Du Seuil.

- (1980). Pouvoirs de l'horreur. Essai sur l'abjection. París: Du Seuil, Col Tel Quel (Traducción al español: Poderes de la perversión. Trad: Nicolás Rosa y Viviana Ackerman. México: Siglo XXI editores, 1989, 2." edición).

- (1983). Histoires d'amour. París: Denoël, Col. L' infini (Traducción al español: Historias de amor. México: Siglo XXI Editores, 1988).

- (1985). Au comencement était l'amour. Psychanalyse et foi. París: Hachette, Col. Textes du XX siècle.

-- (1987). Soleil Noir. Dépression et melancolie. París: Gallimard.

- (1988). Etrangers à nous Mêmes. París. Fayard. (Traducción: Extranjeros para nosotros mismos. Trad: Xavier Gispert. Barcelona: Plaza y Janés Editores, 1991).

- (1993). Les nouvelles maladies de l'âme. París: Fayard (Trad: Alicia Martorell. Madrid: Cátedra, 1995, Col. Teorema).

- (1994). Le temps sensible. Proust et l'experience littéraire. París: Gallimard. 